CLINICAL STUDY

\title{
Osteoprotegerin in relation to body weight, lipid parameters insulin sensitivity, adipocytokines, and C-reactive protein in obese and non-obese young individuals: results from both cross-sectional and interventional study
}

\author{
Marie-Hélène Gannagé-Yared ${ }^{1}$, Cesar Yaghi $^{2}$, Bassem Habre ${ }^{1}$, Simon Khalife ${ }^{3}$, Roger Noun ${ }^{4}$, \\ Myrna Germanos-Haddad ${ }^{5}$ and Viviane Trak-Smayra ${ }^{6}$ \\ ${ }^{1}$ Department of Endocrinology, ${ }^{2}$ Department of Gastroenterology, ${ }^{3}$ Department of Biostatistics, ${ }^{4}$ Laboratory of Immunology, ${ }^{5}$ Department of General \\ Surgery and ${ }^{6}$ Department of Pathology, Saint-Joseph University, Beirut, Lebanon
}

(Correspondence should be addressed to M-H Gannagé-Yared who is now at Division of Endocrinology, Htel-Dieu de France Hospital, Adib Ishaac Street, Beirut, Lebanon; Email: mhcyared@terra.net.lb)

\begin{abstract}
Objective: We analyzed the relation of osteoprotegerin (OPG) with insulin sensitivity, lipid profile, serum glutamic pyruvic transaminase (SGPT), adipocytokines, and C-reactive protein (CRP) in obese and non-obese subjects.

Methods: In the study, 170 subjects (106 obese and 64 non-obese, sex ratio female/male $=2.03$ ) were included. Thirty-two obese subjects were reevaluated 6 months after the weight loss induced by bariatric surgery.

Results: OPG did not differ between obese and non-obese subjects (respective mean values 5.17 and $4.96 \mathrm{pmol} / \mathrm{l})$ or according to gender, but was positively correlated with age $(P<0.0001$ for both groups). OPG was statistically higher in 18 obese diabetic subjects compared with non-diabetics $(P=0.03)$. After adjustment for age, no significant correlation was found between OPG and body mass index (BMI), waist, systolic and diastolic blood pressure, cholesterol, triglycerides, high density lipoprotein (HDL) cholesterol, leptin, and adiponectin in both the obese and non-obese subjects. However, OPG was positively correlated with homeostasis model assessment (HOMA) index and SGPT levels in obese subjects at baseline $(r=0.295, r=0.20, P<0.05)$ and after adjustment for age $(r=$ $0.28, r=0.20, P<0.05)$. OPG was also significantly correlated with CRP; this correlation persisted after adjustment for age in obese subjects $(r=0.30, P<0.01)$. In a multivariate analysis in the obese group, HOMA index and CRP were independent predictors of OPG while SGPT was not. Six months post-surgery, OPG did not change, despite a significant reduction in glucose, SGPT, cholesterol, triglycerides, $\mathrm{CRP}$, and leptin values $(P=0.02, P=0.006, P=0.007, P<0.001, P<0.001, P<0.001$ respectively) and a significant increase in adiponectin and HDL values $(P<0.001$ for both variables). Conclusion: Our results show that in obese subjects, OPG is not related to BMI. However, we describe new relationships between OPG and both HOMA index and CRP.
\end{abstract}

European Journal of Endocrinology 158 353-359

\section{Introduction}

Osteoprotegerin $(\mathrm{OPG})$ is a soluble glycoprotein that belongs to the tumor necrosis factor receptor superfamily (1-6). It acts as a decoy soluble receptor for the receptor activator of nuclear factor $\kappa \mathrm{B}$ ligand (RANKL) (2), thus preventing RANKL from binding its receptor on osteoclasts, thereby inhibiting osteoclastogenesis (6-10). OPG is mainly secreted by bone but is also secreted by a variety of different tissues including endothelial and smooth muscle cells $(1,11,12)$. The contribution of skeletal versus non-skeletal OPG to circulating levels is still unclear.

OPG deficiency in mice predisposes to osteoporosis and arterial calcification $(13,14)$. Surprisingly, a prospective study in elderly women yielded the first epidemiological evidence of an association between high levels of OPG and low bone density, fatal stroke, and overall vascular mortality (15). Subsequently, in the general population, OPG was found to be a risk factor for progressive atherosclerosis (16) and to be associated with the severity of coronary atherosclerosis (17-19). This paradoxical increase in OPG was interpreted as a counter regulatory protective response to atherosclerosis.

Despite the above findings, the relationship of OPG with body mass index (BMI), lipid profile, and insulin sensitivity has been the subject of few and controversial reports depending on the study population (20-24). 
In addition, OPG was recently found to be associated with the C-reactive protein (CRP) in subjects with coronary artery disease (CAD) (18), but this association was never looked at in obese subjects or in young healthy non-obese volunteers.

The purpose of this study is to clarify, mainly in an obese population, the relation of OPG with the different cardiovascular risk factors, from both cross-sectional and interventional studies.

\section{Material and methods}

\section{Study population}

The study population consisted of 106 obese patients (35 males and 71 females) for bariatric surgery (vertical banded gastroplasty or Roux-en-Y gastric bypass). Obese subjects were selected as candidates for bariatric surgery if their BMI was higher than 40 or than 35 when associated with comorbidities. In the study, 64 healthy non-obese subjects (21 males and 43 females) recruited based on voluntary enrolment were also included.

The study was approved by our hospital Ethics Committee. Subjects gave a written informed consent to participate in the study and completed a written form concerning demographic characteristics and current medications.

We measured each subject's weight, height, and waist, and systolic and diastolic blood pressure (SBP and DBP respectively). SBP and DBP were taken after half an hour of rest. BMI was calculated as weight (in kilograms) divided by height (in meters) squared. Waist circumference was measured midway between the lowest rib and the iliac crest.

\section{Methods}

Blood samples were obtained after an overnight fasting. Serum chemistry was performed on the day of collection. Serum was then separated and stored at $-80{ }^{\circ} \mathrm{C}$ for the other measurements. Serum glucose, cholesterol, triglycerides, HDL cholesterol, creatinine, and SGPT were measured using a Kodak automated dry chemistry machine. OPG was measured using a highly sensitive sandwich immunoassay (Immunodiagnostik, Bensheim, Germany). The sensitivity of the assay is $0.14 \mathrm{pmol} / \mathrm{l}$ and the coefficient of variation is $<10 \%$. Ultrasensitive CRP was measured using a commercial kit (Behring, Marburg, Germany); the respective sensitivity and the coefficient of variation of the assay are $0.175 \mathrm{mg} / \mathrm{l}$ and $4 \%$ respectively.

The following hormone measurements were performed using commercially available RIA kits as follows: leptin (Linco Research Inc., St Charles, MO, USA, sensitivity $0.5 \mathrm{ng} / \mathrm{ml}$, intra-assay coefficient of variation 6\%) and adiponectin (Linco Research Inc., sensitivity
$1 \mathrm{ng} / \mathrm{ml}$, intra-assay coefficient of variation $<9.5 \%$ ). OPG, leptin, and adiponectin measurements were performed in duplicate. Insulin measurement was performed using a commercial chemiluminescent assay (Immulite, DPC, LA, USA). The sensitivity of the assay is $2 \mu \mathrm{U} / \mathrm{ml}$ and the intra-assay coefficient of variation $6.4 \%$.

Homeostasis model assessment (HOMA) was taken as a measure of insulin sensitivity using the equation: fasting plasma insulin $(\mathrm{mU} / \mathrm{l}) \times$ glucose $(\mathrm{mmol} / \mathrm{l}) / 22.5$ (25). A high HOMA index indicates low insulin sensitivity while a low HOMA index indicates high insulin sensitivity.

\section{Statistical analysis}

SPSS (version 13.0; Chicago, IL, USA) was used to perform the statistical analysis. The Pearson coefficient was used for linear correlations between variables. The linear correlations were analyzed after logarithmic transformation for most of the variables not normally distributed. A multilinear regression analysis was performed in order to study the independent variables that affect OPG values. An unpaired $t$-test was used to compare mean values between the obese and the nonobese populations. A paired $t$-test was used to compare variables before and after bariatric surgery. A $P$ value $<0.05$ was considered statistically significant for all analysis.

\section{Results}

Baseline clinical and laboratory features of the subjects included in the study are shown in Table 1. The sex ratio (female/male) was 2.04 for the total population, 2.03 for the obese group, and 2.05 for the control non-obese group. Eighteen subjects from the obese group were diabetic while none of the non-obese subjects were diabetic. Two diabetic subjects were on diet therapy, eight on metformin, two on sulfonylureas, seven on combined therapy by metformin and sulfonylureas, and none on thiazolidinedione or insulin therapy.

\section{Relationship between serum OPG levels and clinical parameters}

There was no statistically significant differences in the mean OPG values between the obese and the non-obese groups $(5.17 \pm 1.79 \mathrm{pmol} / \mathrm{l}$ versus $4.96 \pm 1.46 \mathrm{pmol} / \mathrm{l}$, $P=0.42$ respectively). Also, no gender differences were observed $(5.0 \pm 1.64 \mathrm{pmol} / \mathrm{l}$ in females versus $5.28 \pm$ $1.75 \mathrm{pmol} / \mathrm{l}$ in males, $P=0.31$ ). Serum OPG levels were found positively correlated with age $(r=0.41$ and $r=0.47$ in the non-obese and obese populations, $P<0.0001$ respectively). In the 18 diabetic obese subjects, OPG was found statistically higher than in 
Table 1 Baseline clinical and biological characteristics of the 170 subjects.

\begin{tabular}{|c|c|c|c|c|}
\hline & $\begin{array}{l}\text { All the population } \\
\qquad(N=170)\end{array}$ & $\begin{array}{l}\text { Obese subjects } \\
\qquad(N=106)\end{array}$ & $\begin{array}{c}\text { Non-obese subjects } \\
(N=64)\end{array}$ & Significance \\
\hline Sex ratio $(F / M)$ & $(114 / 56)$ & $(71 / 35)$ & $(43 / 21)$ & NS \\
\hline Age (years) & $36.7 \pm 10.23$ & $37.00 \pm 11.37$ & $36.25 \pm 8.12$ & NS \\
\hline BMI $\left(\mathrm{kg} / \mathrm{m}^{2}\right)$ & $35.35 \pm 10.62$ & $42.5 \pm 6.11$ & $23.69 \pm 3.14$ & $<0.0001$ \\
\hline Waist (cm) & $112 \pm 26.7$ & $130 \pm 16.5$ & $84.2 \pm 9.03$ & $<0.0001$ \\
\hline $\mathrm{SBP}(\mathrm{mmHg})$ & $120 \pm 15$ & $125 \pm 13$ & $112 \pm 14.8$ & $<0.0001$ \\
\hline $\mathrm{DBP}(\mathrm{mmHg})$ & $73.5 \pm 8.9$ & $75.1 \pm 7.5$ & $70.5 \pm 10.5$ & 0.002 \\
\hline Osteoprotegerin (pmol/l) & $5.09 \pm 1.68$ & $5.17 \pm 1.79$ & $4.94 \pm 1.47$ & NS \\
\hline CRP $(\mathrm{mg} / \mathrm{l})$ & $7.21 \pm 7.81$ & $10.14 \pm 8.18$ & $2.45 \pm 3.86$ & $<0.0001$ \\
\hline Leptin $(\mu \mathrm{g} / \mathrm{l})$ & $24.55 \pm 16.5$ & $33.58 \pm 14.16$ & $9.52 \pm 5.65$ & $<0.0001$ \\
\hline Adiponectin (mg/l) & $8.34 \pm 5.09$ & $7.47 \pm 5.16$ & $9.8 \pm 4.66$ & 0.0004 \\
\hline Glucose (mmol/l/) & $5.75 \pm 2.26$ & $6.23 \pm 2.74$ & $4.98 \pm 0.43$ & $<0.0001$ \\
\hline Insulin (mU/l) & $9.28 \pm 7.58$ & $10.49 \pm 9$ & $7.22 \pm 3.55$ & 0.007 \\
\hline HOMA index & $2.42 \pm 2.25$ & $2.89 \pm 2.67$ & $1.62 \pm 0.84$ & $<0.0001$ \\
\hline Cholesterol total $(\mathrm{mmol} / \mathrm{l})$ & $5.15 \pm 1.03$ & $5.34 \pm 1$ & $4.87 \pm 1.03$ & 0.004 \\
\hline Triglycerides (mmol/l) & $1.65 \pm 0.94$ & $1.93 \pm 0.94$ & $1.21 \pm 0.76$ & $<0.0001$ \\
\hline HDL cholesterol (mmol/l) & $1.09 \pm 0.37$ & $0.92 \pm 0.26$ & $1.37 \pm 0.35$ & $<0.0001$ \\
\hline SGPT (IU/I) & $38.85 \pm 26.06$ & $43.68 \pm 30.09$ & $31.26 \pm 14.82$ & 0.002 \\
\hline
\end{tabular}

Data are mean and S.D. BMI, body mass index; SBP, systolic blood pressure; DBP, diastolic blood pressure; CRP, C-reactive protein; HDL, high density lipoprotein; SGPT, serum glutamic pyruvic transaminase.

the obese non-diabetic subjects $(5.98 \pm 1.65 \mathrm{pmol} / \mathrm{l}$ versus $5.00 \pm 1.79 \mathrm{pmol} / \mathrm{l}, P=0.03)$. OPG was significantly correlated with waist and SBP only in the obese population $(P<0.01, P<0.05$ respectively); however, these two correlations disappeared after adjustment for age. No correlation was found between OPG and BMI at baseline and after adjustment for age in both the obese and the non-obese populations.

\section{Correlations between serum OPG levels, lipid parameters, HOMA index, adipocytokines, and CRP}

A positive weak correlation was found between OPG and both total cholesterol and triglycerides only in the obese population $(r=0.23$ and 0.22 respectively, $P<0.05)$. These correlations disappeared after adjustment for age. HDL cholesterol was not found to be correlated with OPG values (Table 2).

No significant correlation was found between OPG and HOMA index in the non-obese population. However, in the obese population, OPG was positively correlated with HOMA index, fasting glucose, and SGPT levels $(r=0.295, P<0.01 ; r=0.29, P<0.01 ; r=0.20$, $P<0.05$ respectively) (Fig. 1 ). These correlations persisted after adjustment for age $(r=0.28, P=0.004$; $r=0.22, P<0.05 ; r=0.20, P<0.05$ respectively). The correlation between OPG and HOMA index persisted after adjustment for both age and diabetes $(P=0.01)$. No significant correlations were found between OPG and serum adiponectin or leptin levels in both the obese and the non-obese populations (Table 2).

Finally, OPG is correlated with CRP in both the obese and the non-obese populations $(r=0.25, P<0.01$, $r=0.28, P=0.05$ respectively), this correlation persisted after adjustment for age only in the obese population $(r=0.3, P=0.002)$ (Table 2, Fig. 2).

\section{Multiple regression analysis in the obese population with OPG as a dependant variable}

A multiple regression analysis was performed in order to look at the independent variables that may explain the OPG variability. The three main variables that were

Table 2 Baseline coefficients of correlations between osteoprotegerin (OPG) and hormonal, metabolic and anthropometric factors (B1), and partial coefficients of correlations after correction for age (B2).

\begin{tabular}{|c|c|c|c|c|}
\hline & \multicolumn{2}{|c|}{$\begin{array}{l}\text { Non-obese } \\
\text { population }\end{array}$} & \multicolumn{2}{|c|}{$\begin{array}{c}\text { Obese } \\
\text { population }\end{array}$} \\
\hline & B1 & B2 & B1 & B2 \\
\hline Age (years) & $0.41^{\ddagger}$ & NA & $0.47^{\ddagger}$ & NA \\
\hline $\mathrm{BMl}\left(\mathrm{kg} / \mathrm{m}^{2}\right)$ & 0.12 & 0.002 & 0.15 & 0.156 \\
\hline Waist (cm) & -0.02 & -0.17 & $0.277^{\dagger}$ & 0.20 \\
\hline $\mathrm{SBP}(\mathrm{mmHa})$ & 0.02 & -0.04 & $0.21^{\mathrm{a}}$ & 0.09 \\
\hline $\mathrm{DBP}(\mathrm{mmHg})$ & 0.20 & 0.08 & $0.12^{\mathrm{a}}$ & 0.009 \\
\hline Insulin (mU/l) & 0.12 & 0.13 & $0.16^{a}$ & 0.18 \\
\hline HOMA index & 0.15 & 0.15 & $0.295^{\star}$ & $0.28^{\dagger}$ \\
\hline Glucose $(\mathrm{mmol} / \mathrm{l})$ & 0.18 & 0.11 & $0.29^{\dagger}$ & $0.22^{*}$ \\
\hline Cholesterol total $(\mathrm{mmol} / \mathrm{l})$ & 0.08 & -0.12 & $0.23^{*}$ & 0.13 \\
\hline Triglycerides $(\mathrm{mmol} / \mathrm{l})$ & $-0.04^{a}$ & -0.16 & $0.22^{a, *}$ & 0.11 \\
\hline $\mathrm{HDL}$ cholesterol $(\mathrm{mmol} / \mathrm{l})$ & -0.05 & -0.025 & $0.04^{\mathrm{a}}$ & 0.04 \\
\hline SGPT (IU/I) & -0.04 & -0.04 & $0.20^{\mathrm{a}, \star}$ & $0.20^{*}$ \\
\hline CRP $(\mathrm{mg} / \mathrm{l})$ & $0.28^{\mathrm{a}, *}$ & 0.17 & $0.25^{a, \dagger}$ & $0.30^{\dagger}$ \\
\hline Leptin $(\mu \mathrm{q} / \mathrm{l})$ & 0.21 & 0.20 & -0.1 & -0.04 \\
\hline Adiponectin (mg/l) & -0.04 & 0.12 & $0.03^{a}$ & -0.02 \\
\hline
\end{tabular}

${ }^{\star} P<0.05 ;{ }^{\dagger} P<0.01 ;{ }^{\ddagger} P<0.001$. NA, not applicable. BMI, body mass index; $\mathrm{SBP}$, systolic blood pressure; DBP, diastolic blood pressure; HDL, high density lipoprotein; SGPT, serum glutamic pyruvic transaminase; CRP, C-reactive protein.

${ }^{\text {a }}$ Pearson coefficient correlation was used after logarithmic transformation for these variables. 


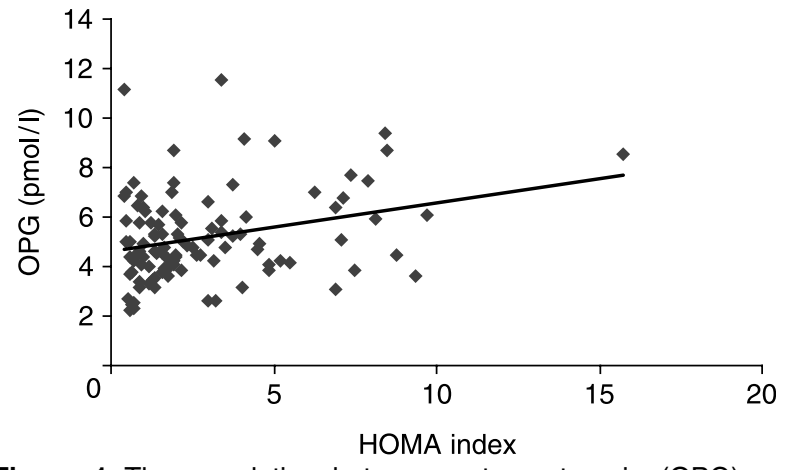

Figure 1 The correlation between osteoprotegerin (OPG) and HOMA index in obese subjects $(r=0.295, P<0.01)$.

statistically significantly correlated with OPG after adjustment for age (SGPT, HOMA index, and CRP) were introduced in the model. CRP and HOMA index were found to be independent predictors of OPG $(P=0.014$ and $P=0.011$ respectively) while SGPT was not $(P=0.42$; Table 3$)$.

\section{Effect of weight loss on serum OPG and other variables}

At 6 months post-surgery, the mean weight loss was $23.5 \%$. This weight loss was not associated with a change in the OPG values but was associated with a significant reduction in glucose, SGPT, cholesterol, triglycerides, CRP, and leptin values $(P=0.02$, $P=0.006, P=0.007, P<0.001, P<0.001, P<0.001$ respectively) and with a significant increase in adiponectin and HDL values $(P<0.001$ for both variables). There were no significant changes in insulin levels or HOMA index (Table 4 and Fig. 3).

We then analyzed the difference of each of the above statistically significant variables after correction for the decrease in the BMI. The change of each SGPT, cholesterol, triglycerides, HDL cholesterol, CRP, and leptin is dependent on the decrease in BMI, while the increase in adiponectin was independent $(P<0.0001)$.

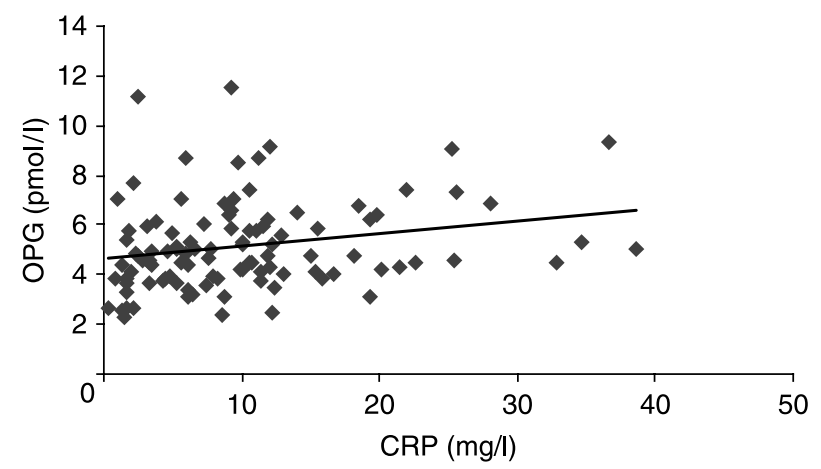

Figure 2 The correlation between osteoprotegerin (OPG) and C-reactive protein (CRP) in obese subjects $(r=0.25, P<0.01)$.
Table 3 Multiple regression analysis in obese subjects with osteoprotegerin (OPG) as a dependent variable.

\begin{tabular}{lclc}
\hline & Parameter estimate & s.E.M. & Significance \\
\hline Constant & 3.91 & 0.38 & $<0.001$ \\
SGPT (IU/l) & 0.005 & 0.006 & 0.42 \\
CRP (mg/l) & 0.051 & 0.02 & 0.014 \\
HOMA index & 0.17 & 0.06 & 0.011 \\
\hline
\end{tabular}

SGPT, serum glutamic pyruvic transaminase; CRP, C-reactive protein.

\section{Discussion}

Our study shows that in a young obese and non-obese population, OPG is strongly related to age. In the obese population, after adjustment for age, OPG remained positively associated with HOMA index, fasting glucose, SGPT, and CRP values, while no relationship with BMI or lipid parameters was observed. In addition, OPG did not vary after a 6-month induced weight loss by bariatric surgery. OPG was also not found to be correlated with leptin or adiponectin values.

The strong positive relation we found between age and OPG was previously described in men $(17,26,27)$, elderly women $(15,23)$, and diabetic subjects $(27)$ and has been interpreted as a compensatory mechanism counteracting the age progression of bone resorption and atherosclerosis $(16,17,19,28)$. This increase was also linked to the expected modifications in renal function observed with age. We found in the present study that this relation is also present at younger ages, suggesting that, in addition to the above explanations, other not yet identified factors linked to age may explain this increase.

The absence of relationship between BMI and OPG observed in our study was previously reported. Two recent studies in Japanese postmenopausal and Korean healthy women $(20,23)$ did not find any relationship between these two parameters. Conversely, a recent study in obese subjects (24) reported lower serum OPG values in comparison with normal-weight controls; the authors explained this finding by a lower activity of osteoclast in obesity. Surprisingly, in this same report, weight loss induces a further decrease in OPG attributed to lower parathyroid hormone and higher $25(\mathrm{OH}) \mathrm{D}$ levels after weight loss. Our results from the interventional study did not show any variation in the OPG values, despite the major changes in BMI, leptin, adiponectin, and CRP. Differences in the timing of reevaluation after weight loss ( 3 months in the Holecki study, 6 months in our study), a greater weight loss secondary to surgery in our study, or other unknown factors could explain this difference between our study and the Holeki study. We also speculate that the circulating OPG values obtained after weight loss could be the result of different OPG sources (lower liver and adipose tissue production associated with higher skeletal production) explaining a neutral effect of weight reduction on OPG values. 
Table 4 Effect of weight loss at 6 months on anthropometric and biochemical variables.

\begin{tabular}{lccc}
\hline & At baseline & $\mathbf{6}$ months post-surgery & Significance \\
\hline BMI $\left(\mathrm{kg} / \mathrm{m}^{2}\right)$ & $40.67 \pm 4.69$ & $31.1 \pm 4.22$ & $<0.001$ \\
Osteoprotegerin $(\mathrm{pmol} / \mathrm{l})$ & $5.11 \pm 1.86$ & $5.26 \pm 1.83$ & $\mathrm{NS}$ \\
CRP $(\mathrm{mg} / \mathrm{l})$ & $9.74 \pm 8.27$ & $3.86 \pm 4$ & $<0.001$ \\
Leptin $(\mu \mathrm{g} / \mathrm{l})$ & $34.45 \pm 13.69$ & $15.03 \pm 8.24$ & $<0.001$ \\
Adiponectin $(\mathrm{mg} / \mathrm{l})$ & $6.95 \pm 3.85$ & $11.77 \pm 5.14$ & $<0.001$ \\
Insulin $(\mathrm{mU} / \mathrm{l})$ & $8.52 \pm 6.08$ & $8.73 \pm 5.05$ & $\mathrm{NS}$ \\
HOMA index & $2.55 \pm 2.21$ & $2.00 \pm 1.19$ & $\mathrm{NS}$ \\
Cholesterol total $(\mathrm{mmol} / \mathrm{l})$ & $5.47 \pm 1$ & $5.03 \pm 1.27$ & 0.007 \\
Glucose $(\mathrm{mmol} / \mathrm{l})$ & $6.78 \pm 4.14$ & $5.19 \pm 0.71$ & 0.02 \\
Triglycerides $(\mathrm{mmol} / \mathrm{l})$ & $1.76 \pm 0.75$ & $1.31 \pm 0.54$ & $<0.001$ \\
HDL cholesterol $(\mathrm{mmol} / \mathrm{l})$ & $0.94 \pm 0.22$ & $1.14 \pm 0.26$ & $<0.001$ \\
SGPT $(\mathrm{IU} / \mathrm{l})$ & $43.68 \pm 30.09$ & $31.26 \pm 14.82$ & 0.006 \\
\hline
\end{tabular}

Data are mean and S.D. BMI, body mass index; CRP, C-reactive protein; HDL, high density lipoprotein; SGPT, serum glutamic pyruvic transaminase.

The relation of OPG with glucose metabolism has been the subject of several recent studies. OPG was found elevated in diabetic patients similarly to our findings $(15,29)$. The reason for this association is unclear. Two previous reports (in obese subjects (22) and in elderly men (21)) showed a positive relationship between OPG and insulin sensitivity, while a third one in women found no relationship (20); finally, in a fourth study (30), OPG was positively correlated with HOMA index in normal and diabetic subjects. Results of the present study are in line with this last study and show an independent relationship between HOMA index and OPG. The discrepancies between all these studies could be explained by the very small sample size of the first study (the subgroup of subjects with high HOMA index constituted of only 12 women). In addition, the second study was performed in a different population (elderly male non-obese population). In the present study, we also did not find any relationship between adiponectin and OPG. Adiponectin was recently found to inhibit the OPG expression in osteoblasts (31). At the opposite, we recently describe in an elderly male population a weak positive association between OPG and adiponectin (21). The contribution of extraskeletal production of OPG may explain these differences.
We also looked at the relationship between OPG and lipid profile. This relation has been the subject of few and controversial studies. In healthy Korean women (20), obese and hypercholesterolemic subjects had higher serum OPG levels. In contrast, Schoppet et al. (17) found a significant inverse correlation between triglycerides and OPG levels in men with CAD despite the fact that OPG was associated with the severity of the disease. Finally, we recently published in a cohort of elderly men, a favorable association between OPG and triglycerides and HDL cholesterol. The neutral relationship between OPG and lipid profile in this study adds more confusion to the subject and could be related to the younger age of our population.

Finally, we looked at the relationship between OPG and both SGPT and CRP values. We found, in our obese group, a strong and independent relationship between OPG and CRP. CRP is an acute-phase protein produced predominantly by hepatocytes under the influence of cytokines. The relationship between CRP and OPG was recently studied in subjects with CAD (18), diabetes (30), and long-lived subjects (32) but has never been looked at in obese subjects. On the other hand, despite the positive relationship that we found in our obese group between OPG and SGPT, SGPT was not found to

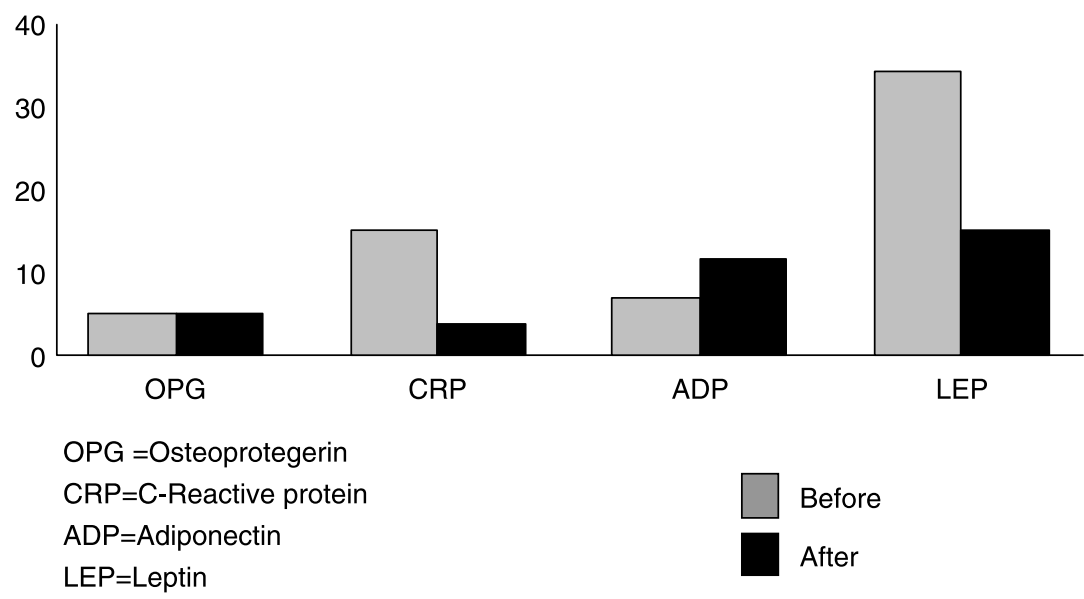

Figure 3 Effect of weight loss induced by bariatric surgery at 6 month on serum osteoprotegerin, CRP, adiponectin, and leptin. 
be an independent predictor of OPG suggesting that, at least in healthy obese subjects, there is no direct relationship between OPG and liver function. The relationship between OPG and liver function has never been looked at in subjects without liver disease. Conversely, recent studies on patients affected by chronic liver disease have shown increased OPG levels (33-35). This relationship was not found to be related to decreased bone mineral density (35), suggesting that OPG may be synthesized by the liver as it is assumed by Simonet et al. (1). Further studies are probably needed to elucidate the relationship between liver function and OPG values in normal subjects or subjects affected by fatty liver disease.

It is surprising to see that, despite the increasing recent number of reports linking OPG to a risk factor for progressive atherosclerosis and cardiovascular disease, OPG was not found to be related to obesity or unfavorable lipid profile. It is also still unclear if OPG represents a compensatory mechanism to counteract the atherosclerotic process or if OPG is an active compound in the atherosclerotic process. The finding of a link between OPG and CRP suggests a possible involvement of OPG in the process of atherosclerosis through an inflammatory process.

In conclusion, our results show that in a healthy obese population, OPG is not associated with BMI and lipid profile. OPG was found to be positively and independently associated with insulin sensitivity and CRP values suggesting a new link between the OPG/RANKL system and both liver and adipose tissue. It should also be mentioned that these results were assessed in a selected obese population. Further research is needed to look at these effects in other populations and to elucidate some additional actions of OPG outside the bone and the vascular system.

\section{Acknowledgements}

This research was supported by the 'Conseil de Recherche de l'Université Saint-Joseph’ (FM 122).

\section{References}

1 Simonet WS, Lacey DL, Dunstan CR, Kelley M, Chang MS, Luthy R, Nguyen HQ, Wooden S, Bennett L, Boone T, Shimamoto G, DeRose M, Elliott R, Colombero A, Tan HL, Trail G, Sullivan J, Davy E, Bucay N, Renshaw-Gegg L, Hughes TM, Hill D, Pattison W, Campbell P, Sander S, Van G, Tarpley J, Derby P, Lee R \& Boyle WJ. Osteoprotegerin: a novel secreted protein involved in the regulation of bone density. Cell 199789 309-319.

2 Lacey DL, Timms E, Tan HL, Kelley MJ, Dunstan CR, Burgess T, Elliott R, Colombero A, Elliott G, Scully S, Hsu H, Sullivan J, Hawkins N, Davy E, Capparelli C, Eli A, Qian YX, Kaufman S, Sarosi I, Shalhoub V, Senaldi G, Guo J, Delaney J \& Boyle WJ. Osteoprotegerin ligand is a cytokine that regulates osteoclast differentiation and activation. Cell 199893 165-176.
3 Mizuno A, Amizuka N, Irie K, Murakami A, Fujise N, Kanno T, Sato Y, Nakagawa N, Yasuda H, Mochizuki S, Gomibuchi T, Yano K, Shima N, Washida N, Tsuda E, Morinaga T, Higashio K \& Ozawa H. Severe osteoporosis in mice lacking osteoclastogenesis inhibitory factor/osteoprotegerin. Biochemical and Biophysical Research Communications 1998247 610-615.

4 Bucay N, Sarosi I, Dunstan CR, Morony S, Tarpley J, Capparelli C, Scully S, Tan HL, Xu W, Lacey DL, Boyle WJ \& Simonet WS. Osteoprotegerin-deficient mice develop early onset osteoporosis and arterial calcification. Genes and Development 199812 1260-1268.

5 Yasuda H, Shima N, Nakagawa N, Yamaguchi K, Kinosaki M, Mochizuki S, Tomoyasu A, Yano K, Goto M, Murakami A, Tsuda E, Morinaga T, Higashio K, Udagawa N, Takahashi N, Suda T, Yasuda H, Shima N \& Nakagawa N. Osteoclast differentiation factor is a ligand for osteoprotegerin/osteoclastogenesis-inhibitory factor and is identical to TRANCE/RANKL. PNAS 199895 3597-3602.

6 Hofbauer LC \& Heufelder AE. The role of receptor activator of nuclear factor-kB ligand and osteoprotegerin in the pathogenesis and treatment of metabolic bone diseases. Journal of Clinical Endocrinology and Metabolism 200085 2355-2363.

7 Tsuda E, Goto M, Mochizuki S, Yano K, Kobayashi F, Morinaga T \& Higashio K. Isolation of a novel cytokine from human fibroblasts that specifically inhibits osteoclastogenesis. Biochemical and Biophysical Research Communications 1997234 137-142.

8 Kwon BS, Wang S, Udagawa N, Haridas V, Lee ZH, Kim KK, Oh KO, Greene J, Li Y, Su J, Gentz R, Aggarwal BB \& Ni J. TR1, a new member of the tumor necrosis factor receptor superfamily, induces fibroblast proliferation and inhibits osteoclastogenesis and bone resorption. FASEB Journal 199812 845-854.

9 Kong YY, Yoshida H, Sarosi I, Tan HL, Timms E, Capparelli C, Morony S, Oliveira-dos-Santos AJ, Van G, Itie A, Khoo W, Wakeham A, Dunstan CR, Lacey DL, Mak TW, Boyle WJ \& Penninger JM. OPGL is a key regulator of osteoclastogenesis, lymphocyte development and lymph-node organogenesis. Nature 1999397 315-323.

10 Koshla S. Minireview: the OPG/RANKL/RANK system. Endocrinology 200112 1260-1268.

11 Hofbauer LC, Shui C, Riggs BL, Dunstan CR, Spelsberg TC, O'Brien T \& Khosla S. Effects of immunosuppressants on receptor activator of NF-B ligand and osteoprotegerin production by human osteoblastic and coronary artery smooth muscle cells. Biochemical and Biophysical Research Communications 2001280 334-339.

12 Collin-Osdoby P, Rothe L, Anderson F, Nelson M, Maloney W \& Osdoby P. Receptor activator of NF-B and osteoprotegerin expression by human microvascular endothelial cells, regulation by inflammatory cytokines, and role in human osteoclastogenesis. Journal of Biological Chemistry 2001276 20659-20672.

13 Schoppet M, Preissner KT \& Hofbauer LC. RANK Ligand and Osteoprotegerin: Paracrine regulators of bone metabolism and vascular function. Arteriosclerosis, Thrombosis, and Vascular Biology 200222 549-553.

14 Bucay N, Sarosi I, Dunstan CR, Morony S, Tarpley J, Capparelli C, Scully S, Tan HL, Xu W, Lacey DL, Boyle WJ \& Simonet WS. Osteoprotegerin deficient mice develop early onset osteoporosis and arterial calcification. Genes and Development 199812 1260-1268.

15 Browner WS, Lui LY \& Cummings SR. Associations of serum osteoprotegerin levels with diabetes, stroke, bone density, fractures, and mortality in elderly women. Journal of Clinical Endocrinology and Metabolism 200186 631-637.

16 Kiechl S, Schett G, Wenning G, Redlich K, Oberhollenzer M, Mayr A, Santer P, Smolen J, Poewe W \& Willeit J. Osteoprotegerin is a risk factor for progressive atherosclerosis and cardiovascular disease. Circulation 2004109 2175-2180.

17 Schoppet M, Sattler AM \& Schaefer JR. Increased osteoprotegerin serum levels in men with coronary artery disease. Journal of Clinical Endocrinology and Metabolism 200388 1024-1028.

18 Rhee EJ, Lee WY, Kim SY, Kim BJ, Sung KC, Kim BS, Kang JH, Oh KW, Oh ES, Baek KH, Kang MI, Woo HY, Park HS, Kim SW, 
Lee MH \& Park JR. Relationship of serum osteoprotegerin levels with coronary artery disease severity, left ventricular hypertrophy and C-reactive protein. Clinical Science 2005108 237-243.

19 Jono S, Ikari Y, Shioi A, Mori K, Miki T, Hara K \& Nishizawa Y. Serum osteoprotegerin levels are associated with the presence and severity of coronary artery disease. Circulation 2002106 1192-1194.

20 Oh ES, Rhee EJ, Oh KW, Lee WY, Baek KH, Yoon KH, Kang MI, Yun EJ, Park CY, Choi MG, Yoo HJ \& Park SW. Circulating osteoprotegerin levels are associated with age, waist-to-hip ratio, serum total cholesterol, and low density lipoprotein cholesterol levels in healthy Korean women. Metabolism $2003 \mathbf{5 4} 49-54$.

21 Gannagé-Yared MH, Fares F, Semaan M, Khalife S \& Jambart S. Circulating osteoprotegerin is correlated with lipid profile, insulin sensitivity, adiponectin and sex steroids in an ageing male population. Clinical Endocrinology $2006 \mathbf{6 4} 652-658$.

22 Ugur-Altun B, Altun A, Gerenli M \& Tugrul A. The relationship between insulin resistance assessed by HOMA-IR and serum osteoprotegerin levels in obesity. Diabetes Research and Clinical Practice $200568217-222$.

23 Uemura H, Yasui T, Miyatani Y, Yamada M, Hiyoshi M, Arisawa K \& Irahara M. Circulating osteoprotegerin is associated with age and systolic blood pressure, but not with lipid profile or fasting glucose, in postmenopausal women. Menopause $200815180-184$.

24 Holecki M, Zahorska-Markiewicz B, Janowska J, Nieszporek T, Wojaczynska-Stanek K, Zak-Golab A \& Wiecek A. The influence of weight loss on serum osteoprotegerin concentration in obese perimenopausal women. Obesity 200715 1925-1929.

25 Matthews DR, Hosker JP, Rudenski AS, Naylor BA, Treacher DF \& Turner RC. Homeostasis model asssessment: insulin resistance and beta-cell function from fasting plasma glucose and insulin concentrations in man. Diabetologia $1985 \mathbf{2 8} 412-419$.

26 Szulc P, Hofbauer LC, Heufelder AE, Roth S \& Delmas PD. Osteoprotegerin serum in men: correlation with age, estrogen, and testosterone status. Journal of Clinical Endocrinology and Metabolism $2001863162-3165$.

27 Anand DV, Lahiri A, Lim E, Hopkins D \& Corder R. The relationship between plasma osteoprotegerin levels and coronary artery calcification in uncomplicated type 2 diabetic subjects. Journal of the American College of Cardiology 200647 1850-1857.
28 Sattler AM, Schoppet M, Schaefer LC \& Hofbauer LC. Novel aspects on RANK ligand and osteoprotegerin in osteoporosis and vascular disease. Calcified Tissue International 200474 103-106.

29 Xiang GD, Xu L, Zhao LS, Yue L \& Hou J. The relationship between plasma osteoprotegerin and endothelium-dependent arterial dilation in type 2 diabetes. Diabetes 200655 2126-2131.

30 Kim SM, Lee J, Ryu OH, Lee KW, Kim HY, Seo JA, Kim SG, Kim NH, Baik SH, Choi DS \& Choi KM. Serum osteoprotegerin levels are associated with inflammation and pulse wave velocity. Clinical Endocrinology $200563594-598$.

31 Luo XH, Guo LJ, Xie H, Yuan LQ, Wu XP, Zhou HD \& Liao EY. Adiponectin stimulates RANKL and inhibits OPG expression in human osteoblasts through the MAPK signalling pathway. Journal of Bone and Mineral Research 200621 1648-1658.

32 Mazziotti G, Amato G, Sorvillo F, Piscopo M, Rizzo MR, Lalli E, Iride L, Cioffi M, Molinari AM, Paolisso G \& Carella C. Increased serum osteoprotegerin values in long-lived subjects: different effects of inflammation and bone metabolism. European Journal of Endocrinology $2006 \mathbf{1 5 4} 373-377$.

33 Gaudio A, Lasco A, Morabito N, Atteritano M, Vergara C, Catalano A, Fries W, Trifiletti A \& Frisina N. Hepatic osteodystrophy: does the osteoprotegerin/receptor activator of nuclear factor-kB ligand system play a role. Journal of Endocrinological Investigation $2005 \mathbf{2 8}$ 677-682.

34 Moschen AR, Kaser A, Stadlmann S, Millonig G, Kaser S, Muhllechner P, Habior A, Graziadei I, Vogel W \& Tilg H. The RANKL/OPG system and bone mineral density in patients with chronic liver disease. Journal of Hepatology 200543 973-983.

35 Garcia-Valdecasas-Campelo E, Gonzalez-Reimers E, SantolariaFernandez F, De la Vega-Prieto MJ, Milena-Abril A, SanchezPerez MJ, Martinez-Riera A \& Gomez-Rodriguez Mde L. Serum osteoprotegerin and RANKL levels in chronic alcoholic liver disease. Alcohol and Alcoholism 20064 261-266.

Received 13 November 2007

Accepted 3 December 2007 